\title{
Rate of elective cholecystectomy and the incidence of severe gallstone disease
}

\section{David R. Urbach, Thérèse A. Stukel}

\section{Abstract}

Background: The use of elective cholecystectomy has increased dramatically following the widespread adoption of laparoscopic cholecystectomy. We sought to determine whether this increase has resulted in a reduction in the incidence of severe complications of gallstone disease.

Methods: We examined longitudinal trends in the populationbased rates of severe gallstone disease from 1988 to 2000, using a quasi-experimental longitudinal design to assess the effects of the large increase in elective cholecystectomy rates after 1991 among people aged 18 years and older residing in Ontario. We also measured the rate of hospital admission because of acute diverticulitis, to control for secular trends in the use of hospital care for acute abdominal diseases.

Results: The adjusted annual rate of elective cholecystectomy per 100000 population increased from 201.3 (95\% confidence interval [Cl] 197.0-205.8) in 1988-1990 to $260.8(95 \% \mathrm{Cl}$ 257.1-264.5) in 1992-2000 (rate ratio [RR] 1.35, 95\% Cl $1.32-1.38, p<0.001)$. An anomalously high number of elective cholecystectomies were performed in 1991. Overall, the annual rate of severe gallstone diseases (acute cholecystitis, acute biliary pancreatitis and acute cholangitis) declined by $10 \%$ (RR $0.90,95 \% \mathrm{Cl} 0.88-0.91$ ) for $1992-2000$ as compared with 1988-1991. This decline was entirely due to an $18 \%$ reduction in the rate of acute cholecystitis (RR $0.82,95 \%$ $\mathrm{Cl}$ 0.80-0.84).

Interpretation: The increase in the rate of elective cholecystectomy that occurred following the introduction of laparoscopic cholecystectomy in 1991 was associated with an overall reduction in the incidence of severe gallstone disease that was entirely attributable to a reduction in the incidence of acute cholecystitis.

CMAJ 2005;172(8):1015-9

A fter the widespread introduction of laparoscopic cholecystectomy in 1991, the rate of cholecystectomy in North America increased by $30 \%$ to $60 \%,{ }^{1-3}$ primarily because of higher rates of elective operations. ${ }^{1}$ Although cholecystectomy is not ordinarily indicated in people with asymptomatic gallstones, ${ }^{4,5}$ the decision to perform the procedure is highly discretionary. ${ }^{6}$ It is unclear whether the increased rate of elective cholecystectomy is due to overuse of surgery among people with asymptomatic or minimally symptomatic gallstones, or whether more patients with clinically important gallbladder disease are willing to undergo cholecystectomy with the availability of laparoscopic surgery. ${ }^{7,8}$

Most cholecystectomies are done in people with uncomplicated biliary colic, the most common presentation of symptomatic gallstones. ${ }^{8}$ Severe complications of gallbladder disease, such as acute cholecystitis, acute biliary pancreatitis and acute cholangitis, are potentially life-threatening conditions that require hospital care. Greater use of elective cholecystectomy in people at risk of severe gallstone complications should result in a lower incidence of such complications. We sought to determine whether the increase in the rate of elective cholecystectomy was associated with a reduction in the incidence of severe complications of gallbladder disease.

\section{Methods}

We used data from the Canadian Institute for Health Information (CIHI), the Ontario Health Insurance Plan (OHIP) physician claims database and the Registered Persons Database. We used intercensal age- and sex-specific estimates of the Ontario population. There is $88 \%-96 \%$ agreement between Ontario health databases for the coding of common surgical procedures. These databases have been used to address other clinical questions relating to gallbladder disease. ${ }^{10}$ Our study was conducted with the approval of the Research Ethics Board of the Sunnybrook and Women's College Health Sciences Centre.

We ascertained the rate of elective cholecystectomy and severe gallstone disease between Apr. 1, 1988, and Mar. 31, 2000, in Ontario among people aged 18 years and older. We obtained records on elective cholecystectomy using Canadian Classification of Procedures (CCP) $\operatorname{codes}^{11}$ and categorized procedures as laparoscopic or open. ${ }^{1}$ Hospital admissions because of severe gallstone disease were included if the most responsible diagnosis code according to the International Classification of Diseases, 9th revision, clinical modification (ICD-9-CM), ${ }^{12}$ indicated acute cholecystitis, acute biliary pancreatitis or acute cholangitis. A hospital admission because of acute cholangitis was considered to represent a spontaneous biliary complication only if there was no concomitant code for a periampullary, gastric, or primary or secondary liver tumour (which accounted for $12.9 \%$ of admissions because of acute cholangitis). We excluded cases of acute pancreatitis that were probably caused by alcohol use if a secondary diagnosis code indicated alcohol abuse or intoxication (4.5\%). We also excluded admissions that occurred within 1 week after an endoscopic retrograde cholangiopancreatography (ERCP, 5.6\%) and cases of acute pancreatitis in people who survived and did not have a cholecystectomy or ERCP within 6 months $(54.4 \%$ of admis- 
sions).$^{13}$ Analyses performed without excluding nonbiliary causes of acute pancreatitis and cholangitis yielded similar results and are not reported.

To determine whether a case of acute pancreatitis was due to gallstones, we linked individual records between databases using a unique identifier, which was missing for some hospital admissions between 1988 and 1991 because of changes to the format of the Ontario health card number. We assumed that the proportion of gallstone-related pancreatitis was similar among patients without a valid unique identifier as among those with a valid identifier.

The rate of hospital admission because of severe gallstone disease may have decreased over time if patients were less likely to be admitted with acute abdominal diseases because of improvements in diagnostic tests, availability of effective oral antibiotics or changes in the general approach to hospital care. Therefore, we also assessed the rate of admission because of acute diverticulitis to control for secular trends. Acute diverticulitis is similar to severe gallstone disease in that it is an acute gastrointestinal syndrome that usually requires hospital care; however, it should not

Table 1: Annual rates of elective cholecystectomy and severe gallstone diseases in Ontario from 1988 to 2000

\begin{tabular}{|c|c|c|c|}
\hline \multirow[b]{2}{*}{ Procedure or disease } & \multicolumn{3}{|c|}{ Rate $(95 \% \mathrm{Cl})$ per 100000 population } \\
\hline & & Men & Women \\
\hline \multicolumn{4}{|c|}{ Elective cholecystectomy } \\
\hline \multicolumn{4}{|l|}{ Age group, yr } \\
\hline $18-44$ & 60.9 & $(60.0-61.8)$ & $310.6(308.7-312.6)$ \\
\hline $45-64$ & 209.3 & $(207.0-211.7)$ & $488.3(484.7-491.8)$ \\
\hline$\geq 65$ & 298.7( & $(294.7-302.7)$ & $360.9(357.1-364.7)$ \\
\hline Overall* & 134.6( & $(133.6-135.6)$ & $367.5(365.9-369.1)$ \\
\hline \multicolumn{4}{|l|}{ Acute cholecystitis } \\
\hline \multicolumn{4}{|l|}{ Age } \\
\hline $18-44$ & 23.6 & $(23.0-24.1)$ & $84.4 \quad(83.3-85.4)$ \\
\hline $45-64$ & 92.8 & $(91.2-94.3)$ & $127.5(125.7-129.3)$ \\
\hline$\geq 65$ & 234.5 & (230.9-238.0) & $193.7(190.9-196.4)$ \\
\hline Overall* & 71.5 & $(70.8-72.3)$ & $115.4(114.5-116.3)$ \\
\hline \multicolumn{4}{|c|}{ Acute biliary pancreatitis } \\
\hline \multicolumn{4}{|l|}{ Age } \\
\hline $18-44$ & 7.4 & $(7.0-7.7)$ & $9.7 \quad(9.3-10.0)$ \\
\hline $45-64$ & 21.3 & $(20.6-22.1)$ & $22.5 \quad(21.7-23.2)$ \\
\hline$\geq 65$ & 43.7 & $(42.1-45.2)$ & $37.3 \quad(36.1-38.5)$ \\
\hline Overall* & 16.2 & $(15.8-16.5)$ & $18.0 \quad(17.7-18.4)$ \\
\hline \multicolumn{4}{|l|}{ Acute cholangitis } \\
\hline \multicolumn{4}{|l|}{ Age } \\
\hline $18-44$ & 1.5 & $(1.4-1.7)$ & $2.2 \quad(2.1-2.4)$ \\
\hline $45-64$ & 7.1 & $(6.7-7.5)$ & $6.8 \quad(6.3-7.2)$ \\
\hline$\geq 65$ & 29.4 & $(28.1-30.7)$ & $22.9 \quad(21.9-23.8)$ \\
\hline Overall* & 6.9 & $(6.6-7.1)$ & $7.1 \quad(6.9-7.3)$ \\
\hline \multicolumn{4}{|l|}{ Acute diverticulitis } \\
\hline \multicolumn{4}{|l|}{ Age } \\
\hline $18-44$ & 13.5 & $(13.1-14.0)$ & $8.0 \quad(7.7-8.3)$ \\
\hline $45-64$ & 56.8 & $(55.6-58.1)$ & $67.6 \quad(66.3-68.9)$ \\
\hline$\geq 65$ & 150.6 & (147.8-153.5) & $218.5(215.5-221.4)$ \\
\hline Overall* & 44.2 & $(43.7-44.8)$ & $61.4 \quad(60.8-62.1)$ \\
\hline
\end{tabular}

Note: $\mathrm{Cl}=$ confidence interval.

*Adjusted for age using direct standardization. be affected by changes in the rate of elective cholecystectomy.

Population-based rates and standard errors of elective cholecystectomy and gallbladder diseases were computed according to age group, sex and year. Sex-specific rates were directly standardized according to age. ${ }^{14} \mathrm{We}$ examined trends in the rates of elective cholecystectomy and severe gallbladder diseases using methods for the analysis of clustered longitudinal data consisting of overdispersed logistic regression models, using a log link (to estimate relative rates) ${ }^{15}$ and auto-regressive correlation across years. The unit of analysis was the stratum of 5-year age group, sex and year. The dependent variable was the observed stratum-specific procedure or hospital admission rate. In all models we controlled for age-sex interactions. We incorporated variance overdispersion in the standard error estimates, to account for clustering of patients within age-sex-year strata.

We compared rates and annual trends before and after the introduction of laparoscopic cholecystectomy. First, we estimated the adjusted rates before (1988-1991) and after (1992-2000) laparoscopic cholecystectomy. We then modeled separate trends over the 2 periods to estimate rate ratios, assuming different intercepts and slopes in each period. ${ }^{16-18}$ Models for elective cholecystectomy excluded data for 1991, when an anomalously high number of elective cholecystectomies were performed. As a sensitivity analysis of possible secular trends in admission rates related to acute abdominal conditions, we included the rate of acute diverticulitis in the models. All statistical tests were performed at the $5 \%$ level of significance and were 2 -sided.

\section{Results}

The mean annual population of Ontario aged 18 years or older during the study period was 8.2 million. The annual rates of elective cholecystectomy and of acute cholecystitis, acute biliary pancreatitis, acute cholangitis and acute diverticulitis are presented in Table 1 by age group and sex.

Trends in the rate of laparoscopic and open cholecystectomy are presented in Fig. 1. The adjusted annual rate of elective cholecystectomy per 100000 population increased from 201.3 (95\% confidence interval [CI 197.0-

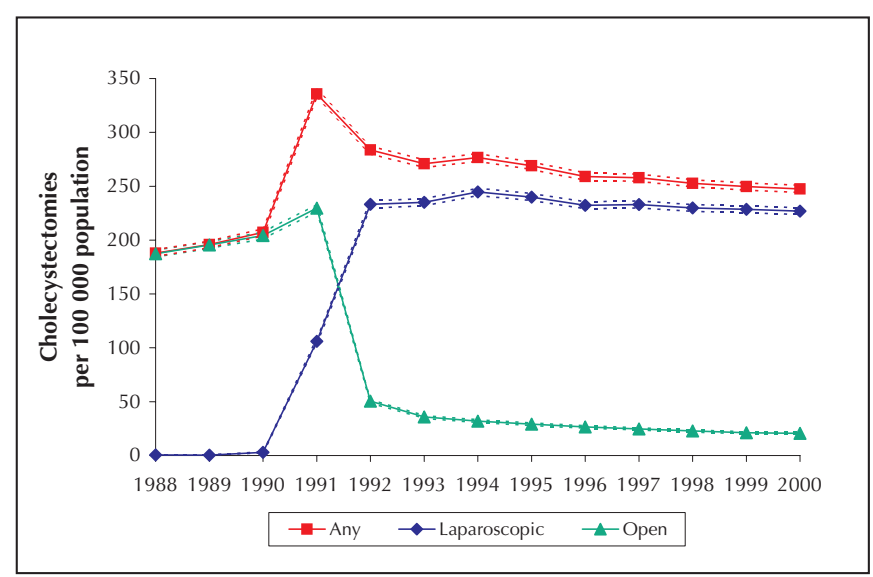

Fig. 1: Rates of elective cholecystectomy (laparoscopic and open) per 100000 population in Ontario from 1988 to 2000. Broken lines indicate 95\% confidence intervals. 
$205.8)$ in $1988-1990$ to 260.8 (257.1-264.5) in 1992-2000, a $35 \%$ overall increase in the procedure rate (rate ratio [RR] $1.35,95 \%$ CI $1.32-1.38, p<0.001$ ). The use of laparoscopic cholecystectomy accounted for less than $1 \%$ of all elective cholecystectomies before 1990, 31.6\% in 1991 and $91.7 \%$ in 2000 .

Trends in the incidence of acute cholecystitis, acute biliary pancreatitis, acute cholangitis and acute diverticulitis are plotted in Fig. 2. After 1991, the average rate of severe gallbladder disease decreased by $10 \%$ (RR 0.90, 95\% CI $0.88-0.91$, Table 2 ). This decline was due primarily to an $18 \%$ reduction in the rate of acute cholecystitis (RR $0.82,95 \%$ CI $0.80-0.84)$. In contrast, the average rates of acute biliary pancreatitis (RR $1.47,95 \%$ CI $1.40-1.54$ ) and acute cholangitis (RR $1.13,95 \%$ CI $1.04-1.23$ ) increased after 1991.

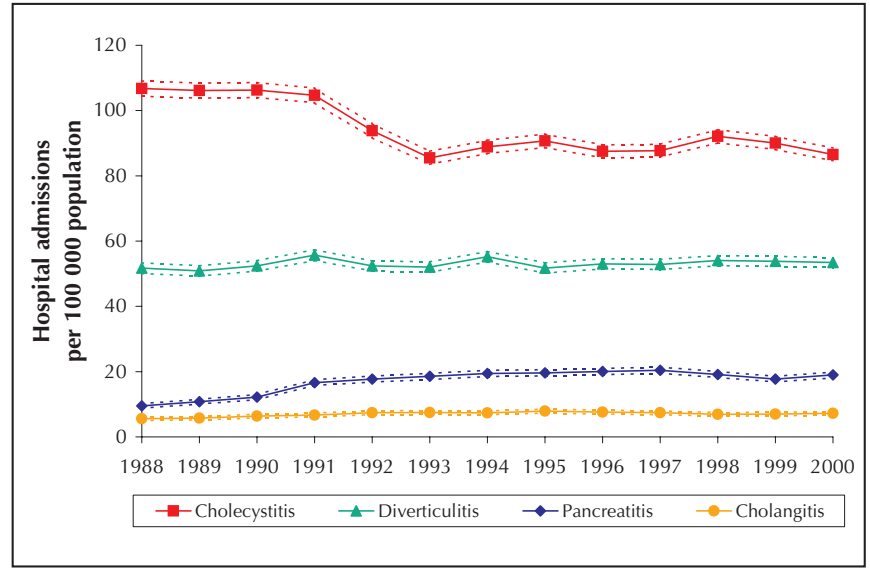

Fig. 2: Rates of acute cholecystitis, acute diverticulitis, acute biliary pancreatitis and acute cholangitis per 100000 population in Ontario from 1988 to 2000. Broken lines indicate 95\% confidence intervals.
Trends for all 3 severe gallstone diseases combined and acute cholecystitis were almost flat both before and after 1991 (Table 2). The rate of acute biliary pancreatitis, which had increased 20\% (95\% CI 16\%-25\%) per year between 1988 and 1991, leveled off after 1992 ( $p$ for change in slopes $<0.001)$. The trend in the rate of acute cholangitis also became level in 1992, after increasing by 6\% (95\% CI $2 \%-10 \%$ ) per year during 1988-1991 ( $p$ for change in slopes $<0.001)$.

Although the rate of acute diverticulitis declined by $0.8 \%$ per year over the study period $(95 \%$ CI $0.3 \%-1.2 \%$, $p=0.001$ ), we found no evidence of a nonlinear trend or an abrupt change after 1991.

\section{Interpretation}

In our study we examined the effect of an increased rate of elective cholecystectomy on the rate of severe complications of gallstone disease, taking advantage of a natural experiment ${ }^{17}$ in Ontario in which rates of elective cholecystectomy rose by $35 \%$ in 1991 owing to the use of laparoscopic surgery. Increased use of cholecystectomy starting in 1991 was associated with an $18 \%$ reduction in the incidence of acute cholecystitis. Although the incidence of acute biliary pancreatitis and cholangitis did not decrease in 1992, the rates leveled off after increasing from 1988 to 1991.

There has been speculation that the introduction of laparoscopic cholecystectomy may have led to inappropriate overuse of cholecystectomy. Although appropriateness of cholecystectomy can be assessed at the individual level by measuring pain relief or satisfaction following surgery, ${ }^{19}$ the dissemination of laparoscopic cholecystectomy was so rapid and unexpected that there was little opportunity to assess changes in appropriateness.

Table 2: Trends in the incidence of acute cholecystitis, acute biliary pancreatitis and acute cholangitis from 1988 to $2000^{*}$

\begin{tabular}{|c|c|c|c|c|}
\hline \multirow[b]{2}{*}{ Measure } & \multicolumn{4}{|c|}{ Outcome } \\
\hline & $\begin{array}{c}\text { All severe } \\
\text { gallstone diseases }\end{array}$ & Acute cholecystitis & $\begin{array}{l}\text { Acute biliary } \\
\text { pancreatitis }\end{array}$ & Acute cholangitis \\
\hline & \multicolumn{4}{|c|}{ Adjusted rate $(95 \% \mathrm{Cl})$ per 100000 population } \\
\hline \multicolumn{5}{|c|}{ Average annual rate } \\
\hline 1988-1991 & $127.8(125.9-129.7)$ & 108.5 (106.7-110.4) & $12.8(12.1-13.5)$ & $6.4(6.0-6.9)$ \\
\hline \multirow[t]{2}{*}{ 1992-2000 } & $114.2(112.9-115.5)$ & $88.1 \quad(86.9-89.3)$ & $18.9(18.3-19.5)$ & $7.2(6.9-7.6)$ \\
\hline & \multicolumn{4}{|c|}{ Rate ratio $(95 \% \mathrm{Cl})$} \\
\hline Change in rate $\dagger$ & $0.90 \quad(0.88-0.91) \S$ & $0.82(0.80-0.84) \S$ & $1.47(1.40-1.54) \S$ & $1.13(1.04-1.23) \uparrow$ \\
\hline \multicolumn{5}{|l|}{ Average trend } \\
\hline 1988-1991‡ & $1.011(1.000-1.023)$ & 0.988 (0.974-1.001) & $1.202(1.156-1.249) \S$ & $1.060(1.025-1.097) \S$ \\
\hline 1992-2000‡ & $0.992(0.987-0.996) \S$ & $0.991(0.987-0.996)$ ฯ & $0.996(0.985-1.006)$ & $0.983(0.969-0.996)$ ฯ \\
\hline
\end{tabular}

*Rates and rate ratios are adjusted for age and sex and were estimated using overdispersed binary regression models.

†Change in average rate for 1992-2000 as compared with average rate for 1988-1991.

$\ddagger$ Average proportional change in annual rate.

$\$ p<0.001$.

ฯ $p<0.01$. 
We found that an increased rate of elective cholecystectomy had a large and immediate effect on the incidence of acute cholecystitis, but not on the incidence of biliary pancreatitis or cholangitis. Patients in whom severe biliary complications develop after presenting with uncomplicated biliary colic are much more likely to have acute cholecystitis as a complication than acute biliary pancreatitis or cholangitis. ${ }^{20}$ Therefore, it is plausible that a higher rate of cholecystectomy among people with biliary colic would result in a lower incidence of acute cholecystitis. Without cholecystectomy, nearly $50 \%$ of patients with biliary colic experience escalation of their symptoms, and $8 \%$ experience severe acute cholecystitis. ${ }^{21}$ In contrast, biliary pancreatitis and cholangitis are caused by the migration of small stones or biliary sludge ${ }^{22}$ from the gallbladder into the bile duct. Cholecystectomy in people with symptomatic gallstones appears to have an immediate benefit in preventing the escalation of milder disease to acute cholecystitis.

We believe that our results support a cause-effect relation for several reasons. The association between increased use of elective cholecystectomy and reductions in the incidence of gallstone complications is biologically plausible. The sudden reduction in the rates of gallstone complications cannot be explained on the basis of secular trends in the incidence of these diseases, other interventions or the use of hospital care for acute abdominal diseases (e.g., acute diverticulitis) during this period. Our findings cannot be explained by a tendency to code acute cholecystitis as biliary colic more frequently after 1991, since the principal results were unchanged after we included emergency hospital admissions because of biliary colic as cases of acute cholecystitis. Also unlikely as an explanation for this decrease is a sudden reduction in the likelihood of physicians admitting patients to hospital who have acute cholecystitis. The rate of hospital admission because of acute diverticulitis, which for mild disease is similar to acute cholecystitis in terms of a physician's discretion to admit a patient to hospital, did not change abruptly after 1991. Finally, error in the definitions of biliary pancreatitis and cholangitis are unlikely to have affected our findings, since the results were essentially unchanged after we repeated the analyses using less restrictive definitions for these diseases.

We did not assess the potential adverse consequences of the increased rate of elective cholecystectomy, such as cholecystectomy-related complications and mortality. Early reports suggested that the risk of serious injury to the bile duct increased immediately following the introduction of laparoscopic cholecystectomy, ${ }^{23,24}$ presumably because of the "learning curve" 25 for adopting a new procedure. Although formal residency training in laparoscopic cholecystectomy has probably reduced the incidence of bile-duct injuries related to inexperience, ${ }^{26}$ laparoscopic cholecystectomy may pose a higher risk of bile-duct injury than conventional surgery. Because of the reduction in the procedure-specific mortality of cholecystectomy associated with laparoscopic surgery, an overall increase in cholecystectomy-related mortality is unlikely. ${ }^{2}$

How can a reduction in the rate of severe gallstone disease be reconciled with the cost in terms of a higher number of elective cholecystectomies? Based on our data, we estimate that the introduction of laparoscopic cholecystectomy led to an additional 59.5 elective cholecystectomies and 13.6 fewer hospital admissions because of severe gallbladder disease per 100000 population per year between 1992 and 2000. Therefore, about 4-5 additional elective cholecystectomies were performed for every case of severe gallstone disease that was potentially prevented. This may represent a favourable trade-off, since cholecystectomy for severe gallstone disease is associated with a higher $\operatorname{cost}^{27}$ and risk of operative death ${ }^{2}$ than is elective cholecystectomy.

In conclusion, the increase in the rate of elective cholecystectomy that occurred following the introduction of laparoscopic cholecystectomy in 1991 was associated with an overall reduction in the incidence of severe gallstone disease that was entirely attributable to a reduction in the incidence of acute cholecystitis. Our findings suggest that a higher rate of elective cholecystectomy may have a net benefit to the health of Canadians with gallbladder disease.

This article has been peer reviewed.

From the Institute for Clinical Evaluative Sciences (Urbach, Stukel); the Department of Health Policy, Management and Evaluation (Urbach, Stukel) and the Department of Surgery (Urbach), University of Toronto; and the Division of Clinical Decision Making and Health Care, University Health Network (Urbach), Toronto, Ont.

Competing interests: None declared.

Contributors: David Urbach drafted the article and contributed substantially to the study conception and design and to the analysis and interpretation of the data. Thérèse Stukel contributed substantially to the study design and to the analysis and interpretation of the data and revised the article for important intellectual content. Both authors gave final approval of the version to be published.

Acknowledgements: We thank Andreas Laupacis and John Marshall for their thoughtful comments on earlier drafts of this manuscript. We are indebted to Ping $\mathrm{Li}$ for her expert assistance with programming and preparing the data sets for analysis.

This research was supported by a Junior Faculty Award from the Surgical Infection Society. David Urbach is a Career Scientist of the Ontario Ministry of Health and Long-Term Care, Health Research Personnel Development Program.

\section{References}

1. Cohen MM, Young W, Theriault ME, Hernandez R. Has laparoscopic cholecystectomy changed patterns of practice and patient outcome in Ontario? CMA7 1996;154(4):491-500.

2. Steiner CA, Bass EB, Talamini MA, Pitt HA, Steinberg EP. Surgical rates and operative mortality for open and laparoscopic cholecystectomy in Maryland. NEngl 7 Med 1994;330:403-8.

3. Legorreta AP, Silber JH, Costantino GN, Kobylinski RW, Zatz SL. Increased cholecystectomy rate after the introduction of laparoscopic cholecystectomy. 7AMA 1993;270:1429-32.

4. Gracie WA, Ransohoff DF. The natural history of silent gallstones: the innocent gallstone is not a myth. N Engl 7 Med 1982;307:798-800.

5. Ransohoff DF, Gracie WA. Treatment of gallstones. Ann Intern Med 1993; 119:606-19.

6. Gentleman JF, Vayda E, Parsons GF, Walsh WN. Surgical rates in subprovincial areas across Canada: rankings of 39 procedures in order of variation. Can F Surg 1996;39:361-7.

7. Escarce JJ, Chen W, Schwartz JS. Falling cholecystectomy thresholds since the introduction of laparoscopic cholecystectomy. 7AMA 1995;273:1581-5.

8. Shea JA, Berlin JA, Bachwich DR, Staroscik RN, Malet PF, McGuckin M, et 
al. Indications for and outcomes of cholecystectomy: A comparison of the pre and postlaparoscopic eras. Ann Surg 1998;227:343-50.

9. Iron K, Goel V, Williams JI. Concordance with hospital discharge abstracts and physician claims for surgical procedures in Ontario (ICES Working Paper Series Report no 42). North York (ON): Institute for Clinical Evaluative Sciences in Ontario; 1995.

10. Mamdani MM, Tu K, van Walraven C, Austin PC, Naylor CD. Postmenopausal estrogen replacement therapy and increased rates of cholecystectomy and appendectomy. CMA7 2000;162(10):1421-4.

11. Canadian Centre for Health Information Nosology Reference Centre. Canadian classification of diagnostic, therapeutic, and surgical procedures. Ottawa: Statistics Canada; 1993.

12. 1999 hospital \& payor ICD-9-CM: international classification of diseases, 9th revision, clinical modification. 5th ed. Salt Lake City: Medicode; 1998.

13. Glazer G, Mann MV. United Kingdom guidelines for the management of acute pancreatitis. British Society of Gastroenterology. Gut 1998;42(Suppl 2): S1-13

14. Keyfitz N. 3. Sampling variance of standardized mortality rates. Hum Biol 1966;38:309-17.

15. McCullagh P, Nelder JA. Generalized linear models. 2nd ed. New York: Chapman and Hall; 1989.

16. Ulm K. A statistical method for assessing a threshold in epidemiological studies. Stat Med 1991;10:341-9.

17. Cook TD, Campbell DT. Quasi-experimentation: design and analysis issues for field settings. Boston: Houghton Mifflin Company; 1979.

18. Veney JE, Kaluzny AD. Evaluation and decision making for bealth services. 3rd ed. Chicago: Health Administration Press; 1998.

19. Traverso LW, Lonborg R, Pettingell K, Fenster LF. Utilization of cholecys- tectomy - a prospective outcome analysis in 1325 patients. 7 Gastrointest Surg 2000;4:1-5.

20. Rutledge D, Jones D, Rege R. Consequences of delay in surgical treatment of biliary disease. Am 7 Surg 2000;180:466-9.

21. McSherry CK, Ferstenberg H, Calhoun WF, Lahman E, Virshup M. The natural history of diagnosed gallstone disease in symptomatic and asymptomatic patients. Ann Surg 1985;202:59-63.

22. Lee SP, Nicholls JF, Park HZ. Biliary sludge as a cause of acute pancreatitis N Engl 7 Med 1992;326:589-93.

23. Southern Surgeons Club. A prospective analysis of 1518 laparoscopic cholecystectomies. N Engl 7 Med 1991;324:1073-8.

24. Adamsen S, Hansen OH, Funch-Jensen P, Schultze S, Stage JG, Wara P. Bile duct injury during laparoscopic cholecystectomy: a prospective nationwide series. 7 Am Coll Surg 1997;184:571-8.

25. Hunter JG. The learning curve in laparoscopic cholecystectomy. Min Inv Therapy Allied Tech 1997;6:24-5.

26. Archer SB, Brown DW, Smith CD, Branum GD, Hunter JG. Bile duct injury during laparoscopic cholecystectomy: results of a national survey. Ann Surg 2001;234:549-59.

27. Glasgow RE, Cho M, Hutter MM, Mulvihill SJ. The spectrum and cost of complicated gallstone disease in California. Arch Surg 2000;135:1021-7.

Correspondence to: Dr. David R. Urbach, 9 Eaton North, Rm. 236A, Toronto General Hospital, 200 Elizabeth St., Toronto ON M5G 2C4; fax 416 340-4211; david.urbach@uhn.on.ca

\section{Writing for CMAJ}

CMAJ publishes papers that advance the understanding of medicine and health care, stimulate debate, educate and entertain. Most submissions arrive unsolicited, and we welcome them. Contributors should consult the instructions for authors on eCMAJ (www.cmaj.ca/misc/ifora.shtml).

Research articles report original findings of interest to a general medical audience. Articles should be no more than 2500 words long. Novel case reports will also be considered for the Research section. Research letters are short (500 words) reports that do not require extensive elaboration with respect to methods and results.

Although most Commentaries are written at our invitation, we welcome unsolicited submissions and suggestions for topics and contributors. Commentaries require a succinct and confident style, a clear point of view and a degree of balance.

The Review section contains comprehensive, peerreviewed summaries of recent advances in basic science or clinical practice (systematic and narrative reviews). Most submissions should be no longer than 2000 words.

Practice contains brief articles (1000-1200 words) that present or review information for physicians in practice. It includes case reports and short papers that do not qualify as original research but remind physicians of important clinical situations. Prospective authors should contact the editors to discuss ideas and projects.
The Left Atrium gives readers room for reflection. Book and film reviews are solicited by the editor. We welcome unsolicited poetry, fiction and creative nonfiction. The writing should be candid, but patient confidentiality must be respected. If you would like to be added to our list of book reviewers or to discuss ideas for contributions, please contact the senior deputy editor, Anne Marie Todkill.

Letters to the Editor commenting on published articles or of general interest are welcome. Brevity is highly prized: submissions should be no more than 250 words long and appropriately referenced. The most effective letters usually raise a single, tersely argued point. Authors whose work is discussed are given an opportunity to respond.

For the unabridged version of Writing for $\mathrm{CMAJ}$, see our Web site at cmaj.ca

Editor, CMAJ

John Hoey, MD

$800663-7336 \times 2118$

john.hoey@cma.ca

To contact other $\mathrm{CMAJ}$ staff members, please consult the masthead at the front of the journal or send an email message to pubs@cma.ca

CMAIVIAMC 